\title{
Isolated foveal hypoplasia
}

\author{
MOSHE D OLIVER,' SHLOMO A DOTAN,' JUAN CHEMKE,' \\ AND FABIAN A ABRAHAM
}

From the 'Eye Department and the 'Genetics Unit, Kaplan Hospital, Rehovot, and the ''Hebrew UniversityHadassah Medical School, Jerusalem, and the ${ }^{3}$ Maurice and Gabriella Goldschlager Eye Institute, Tel Aviv University-Sackler School of Medicine, Chaim Sheba Medical Center, Tel-Hashomer, Israel

SUMmaRY Fifteen patients presented with foveal hypoplasia as an isolated ocular finding. The characteristic findings associated with this entity are a visual acuity of $6 / 21$ or worse, nystagmus, and a typical ophthalmoscopic appearance of the macular area, including absent or abnormal maculofoveal reflexes, unclear definition of the maculofoveal area, and capillaries running abnormally close to the presumed macular area, some of them even crossing the horizontal meridian. Fluorescein angiography revealed a variable and incomplete filtering effect of the choroidal fluorescence in the macular area, suggesting abnormalities in the amount and distribution of macular pigments. The fundal findings of isolated foveal hypoplasia, although typical, are very subtle and often difficult to detect, especially because of the accompanying nystagmus. For this reason we suspect that foveal hypoplasia may be more common than is generally believed.

Foveal hypoplasia has been described in association with other anatomical eye disorders, such as aniridia, albinism, microphthalmus, and achromatopsia. ${ }^{1-3}$ Recently Yoshizumi et al. ${ }^{+}$described a patient with congenital pendular nystagmus, foveal hypoplasia, and bilateral retinal rosettes near the ora serrata. O'Donnell and Pappas described a family with congenital nystagmus and mild foveal hypoplasia associated with presenile cataracts and peripheral corneal pannus.

Only a few cases of foveal hypoplasia as an isolated anatomical finding have been reported. ${ }^{\alpha-9} \mathrm{Holm}^{6}$ described three brothers with nystagmus and foveal hypoplasia; Koyanagi' reported similar findings in a brother and a sister. Uemura and Kumanomido described seven patients with foveal hypoplasia and nystagmus. Recently Curran and Robb ${ }^{4}$ described nine patients with foveal hypoplasia and congenital nystagmus.

We report here on the clinical and laboratory findings in 15 patients with bilateral foveal hypoplasia as an isolated anatomical finding.

\section{Subjects and methods}

Fifteen patients with foveal hypoplasia, congenital Correspondence to Dr M Oliver, Eyc Department, Kaplan Hospital, 76-100 Rehovot, Isracl. nystagmus, and low visual acuity, but without evidence of other ocular disorders, were examined and followed up in the Eye Outpatient Department of the Kaplan Hospital, Rehovot.

In each patient cycloplegic refraction was determined after the instillation of $2 \%$ cyclopentolate drops twice at an interval of half an hour. Subjective refraction was determined a week later. Orthoptic examination, evaluation of colour vision by means of pseudoisochromatic plates, and several dilated fundus examinations were performed in each case. Fluorescein angiography was performed in only seven patients, who were old enough to co-operate. Electroretinograms (ERG) and the visual evoked response (VER) were recorded and measured with the Nicolet CA 1000 apparatus.

Genetic studies of the families of the affected patients were carried out wherever possible. The pedigrees of nine families were investigated and a total of 35 individuals, including the 15 patients of this series, were examined. The family pedigrees of three of our patients could not be obtained.

\section{Results}

Of the 15 patients included in this study six were males and nine were females (Table 1). Their ages ranged from 3 to 46 years. All patients were bilater- 
Table 1 Clinical data of patients with isolated foveal hypoplasia

\begin{tabular}{|c|c|c|c|c|c|}
\hline $\begin{array}{l}\text { Patient no. } \\
\text { sex, age (yr) }\end{array}$ & $\begin{array}{l}\text { Visual } \\
\text { acuity }\end{array}$ & Refraction & $\begin{array}{l}\text { Colour } \\
\text { vision }\end{array}$ & $\begin{array}{l}\text { Orthoptic } \\
\text { examination }\end{array}$ & Electrodiagnostic tests \\
\hline $1, F, 12$ & $\begin{array}{l}6 / 21 \\
6 / 21\end{array}$ & $\begin{array}{l}+2 \cdot 50=+3 \cdot(0) \times 85 \\
+4 \cdot 50=+4 \cdot 25 \times 95\end{array}$ & Normal & Orthophoria & $\begin{array}{l}\text { Large ERG components, normal latency but subnormal } \\
\text { amplitude of VER }\end{array}$ \\
\hline $2, \mathrm{M}, 9$ & $\begin{array}{l}6 / 60 \\
6 / 60\end{array}$ & $\begin{array}{l}+3 \cdot 50=+3 \cdot(0) \times 90 \\
+4 \cdot(0)=+3 \cdot(00) \times 90\end{array}$ & Protanopia & Orthophoria & $\begin{array}{l}\text { Large ERG components, normal latency but subnormal } \\
\text { amplitude of VER }\end{array}$ \\
\hline $3, F, 11$ & $\begin{array}{l}6 / 60 \\
6 / 60\end{array}$ & $\begin{array}{l}-2 \cdot()()=+5 \cdot 50 \times 90 \\
-1 \cdot 50=+3 \cdot 50 \times 100\end{array}$ & Normal & $\begin{array}{l}\text { Alternating } \\
\text { Esotropia }+18^{\wedge}\end{array}$ & Normal ERG, normal latency but subnormal amplitude of VER \\
\hline $4, F, 9$ & $\begin{array}{l}6 / 30 \\
6 / 21\end{array}$ & $\begin{array}{l}-2 \cdot() 0=+2 \cdot 50 \times 120 \\
-0 \cdot 50=+1 \cdot 50 \times 90\end{array}$ & Normal & $\begin{array}{l}\text { Intermittent } \\
\text { Exotropia - } 30^{4}\end{array}$ & Normal latency but subnormal amplitude of VER \\
\hline $5, F, 5$ & $\begin{array}{l}6 / 60 \\
6 / 60\end{array}$ & $\begin{array}{l}-0 \cdot 25=+2 \cdot 75 \times 100 \\
+0 \cdot 25=+2 \cdot 50 \times 90\end{array}$ & Normal & R exotropia $-30^{\Delta}$ & Normal ERG \\
\hline $6, M, 3$ & $\begin{array}{l}6 / 60 \\
6 / 60\end{array}$ & $\begin{array}{l}\text { Plano }=+3 \cdot(0) \times 100 \\
\text { Plano }=+3 \cdot(00 \times 100\end{array}$ & $\begin{array}{l}\text { Not } \\
\text { evaluated }\end{array}$ & Orthophoria & Normal ERG \\
\hline $7, F, 10$ & $\begin{array}{l}6 / 30 \\
6 / 30\end{array}$ & $\begin{array}{l}\times 3 \cdot()(0=+1 \cdot(0) \times 70 \\
+4 \cdot() 0=+1 \cdot 25 \times 85\end{array}$ & Normal & Orthophoria & Normal ERG, normal latency but subnormal amplitude of VER \\
\hline $8, M, 6$ & $\begin{array}{l}6 / 60 \\
6 / 60\end{array}$ & $\begin{array}{l}\text { Plano }=+2 \cdot(0) \times 180 \\
\text { Plano }=+2 \cdot 00 \times 190\end{array}$ & Normal & R esotropia $+30^{\Delta}$ & Normal ERG, normal latency but subnormal amplitude of VER \\
\hline $9, \mathrm{M}, 10$ & $\begin{array}{l}6 / 21+ \\
6 / 21\end{array}$ & $\begin{array}{l}+1 \cdot(0)=+1.75 \times 90 \\
+1 \cdot(0)=1.75 \times 90\end{array}$ & Normal & Lexotropia $-10^{\Delta}$ & Normal ERG, normal latency but subnormal amplitude of VER \\
\hline $10 . \mathrm{F}, 18$ & $\begin{array}{l}6 / 21 \\
6 / 21\end{array}$ & $\begin{array}{l}-6 \cdot(0)=+5 \cdot 50 \times 90 \\
-4 \cdot(0)=+3 \cdot 50 \times 90\end{array}$ & Normal & $\mathrm{R}$ esotropia $+30^{\Delta}$ & Normal ERG, normal latency but subnormal amplitude of VER \\
\hline $11, F, 7$ & $\begin{array}{l}6 / 60 \\
6 / 30\end{array}$ & $\begin{array}{l}+1 \cdot(00=+0.75 \times 180 \\
+1 \cdot 50\end{array}$ & Normal & Orthophoria & Not recorded \\
\hline $12, M, 18$ & $\begin{array}{l}6 / 30 \\
6 / 30\end{array}$ & $\begin{array}{l}-2 \cdot(0)=+3 \cdot 50 \times 90 \\
-2 \cdot(0)=+4 \cdot 50 \times 100\end{array}$ & Normal & Rexotropia $-20^{\Delta}$ & Normal ERG, normal latency but subnormal amplitude of VER \\
\hline $13, F, 32$ & $\begin{array}{l}6 / 30 \\
6 / 60\end{array}$ & $\begin{array}{l}-0 \cdot 5(0=+1 \cdot(0) \times 180 \\
-3 \cdot(0)=+2 \cdot 50 \times 180\end{array}$ & Normal & Lexotropia -20$)^{1}$ & Normal ERG, normal latency but subnormal amplitude of VER \\
\hline $14, F, 46$ & $\begin{array}{l}6 / 60 \\
6 / 60\end{array}$ & $\begin{array}{l}-1 \cdot 50=+3.50 \times 70 \\
+1 \cdot(0)=+1 \cdot(00 \times 90)\end{array}$ & Normal & Orthophoria & Not recorded \\
\hline $15, M, 27$ & $\begin{array}{l}6 / 30- \\
6 / 30\end{array}$ & $\begin{array}{l}\text { Plano }=+2 \cdot 25 \times 90 \\
-1 \cdot 25=+1 \cdot 50 \times 90\end{array}$ & Normal & R cxotropia $>-45^{\wedge}$ & Normal ERG, normal latency but subnormal amplitude of VER \\
\hline
\end{tabular}

ally affected by the disease, and all presented with either pendular or jerk nystagmus which remained horizontal even in vertical gaze. The best corrected visual acuity was in no case better than $6 / 21$; it was $6 / 60$ in six patients, $6 / 30$ in five others, and $6 / 21$ in four. Cycloplegic refraction revealed that 13 eyes (seven patients) had with-the-rule astigmatism of 3.00 dioptres or more. Colour vision was normal in 13 patients, and one male patient had protanopia; one child was too young to be tested. Twelve patients had abnormal head posture, but no typical pattern was evident. Tropia was found in nine patients, esotropia in three of them and exotropia in six.

Indirect ophthalmoscopic examination showed characteristic fundal findings as follows: nerve heads were bilaterally normal; macular and foveal reflexes were absent or abnormal; the retinal capillaries which run from the upper and lower arcades were abnormally close to the presumed foveal area, and some of them even crossed the horizontal meridian (Figs. 1, 2). In two of the seven fluorescein angiograms the intensity of choroidal fluorescence emitted from the presumed macular area was similar to that from other fundal areas (Fig. 3). In four cases, although pigment was evidently present in the

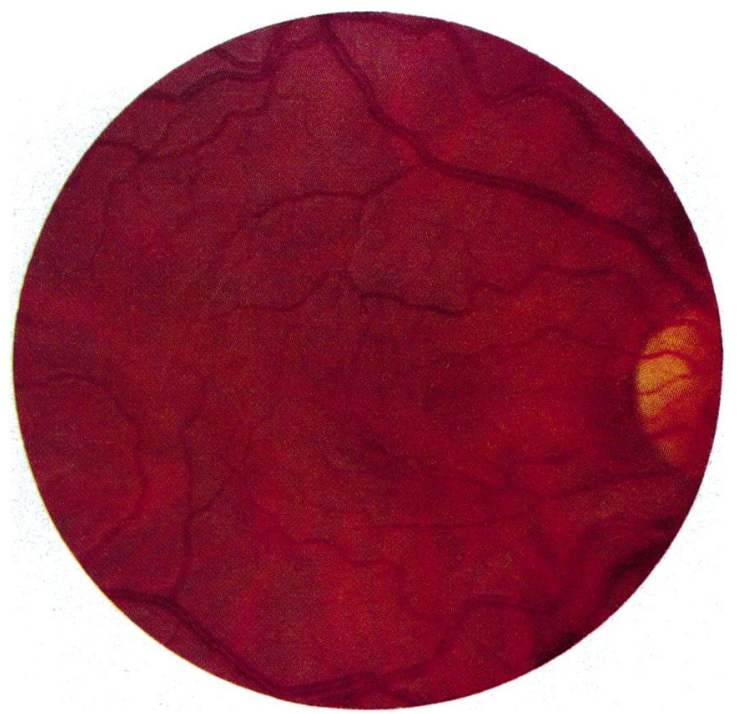

Fig. 1 Fundal appearance of a 9-year-old boy with isolated foveal hypoplasia. Macular and foveal reflexes are absent. The retinal capillaries which run from the upper and lower arcades are abnormally close to the presumed foveal area, and some of them cross the horizontal meridian. 


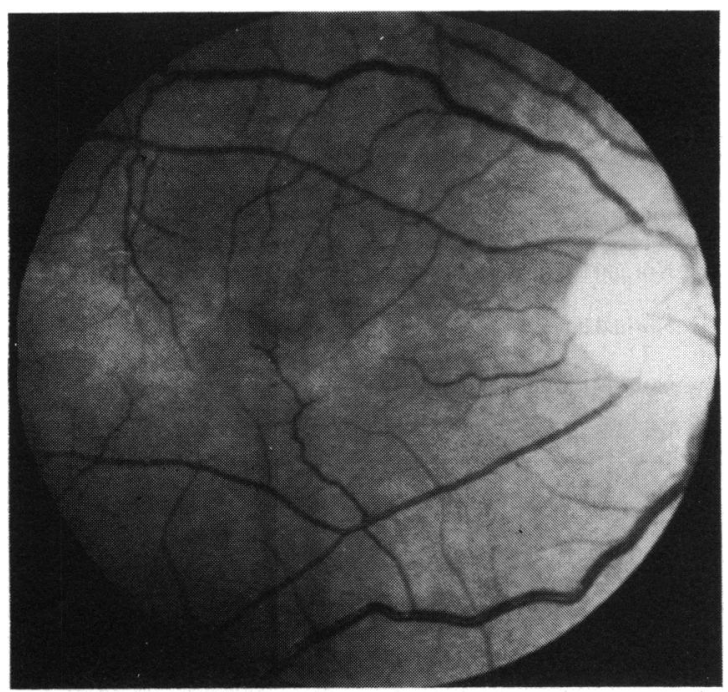

Fig. 2 Red-free picture of the macular area. The maculofoveal area is poorly defined. Capillaries from the upper and lower arcades are abnormally close to the presumed macular area and some of them cross the horizontal meridian.

macular area, there was not enough of it completely to filter the fluorescence from the underlying choroid. In one patient the filtering of the choroidal fluorescence in the macular area was total.

The ERG was performed on 12 patients under photopic conditions and followed for about 15

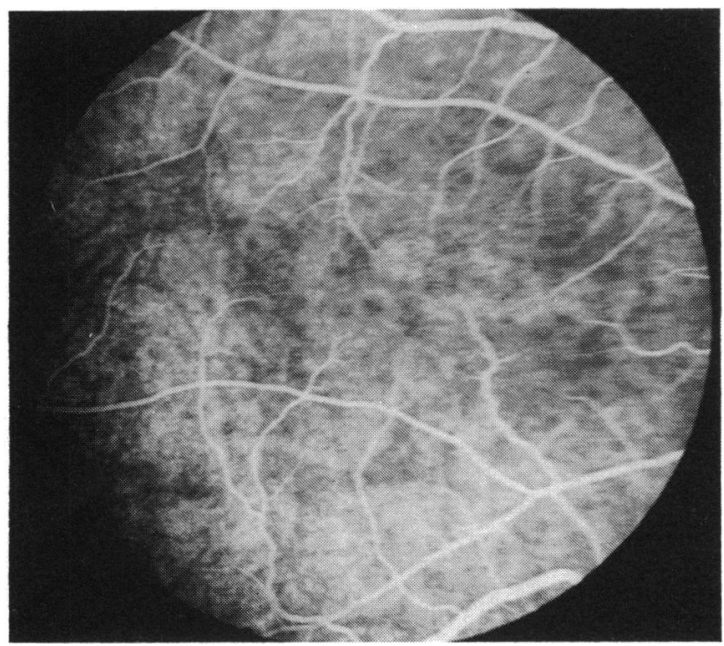

Fig. 3 Fluorescein angiography of the fundus in Fig. 2. The choroidal fluorescence from the maculofoveal area is similar to that from more peripheral parts of the fundus. The normal filter effect associated with the presence of pigments in the macular area is absent. minutes in the dark; full dark adaptation was difficult to achieve. Both photopic and scotopic ERG components were found to be normal in 10 patients and unusually large in two. The VER was determined in 11 patients, all of whom showed normal latency though with slightly subnormal amplitudes.

In the nine families whose pedigrees were studied there were three pairs of affected siblings. We examined 20 additional members of these families, none of whom had foveal hypoplasia. Eight individuals from these families were reported to have some form of visual disturbances, but were not examined, and the possibility that some or all of them had foveal hypoplasia cannot be ruled out. Family members studied were of different ethnic origins, and there were four cases of consanguinity (Fig. 4).

\section{Discussion}

In the absence of other ocular diseases the diagnostic findings common to all patients with foveal hypoplasia are a low visual acuity, never better than $6 / 21$; jerk or pendular nystagmus; and typical ophthalmoscopic and angiographic findings, as discussed below.

Waardenburg described the characteristic fundal appearance in foveal hypoplasia as absence or marked irregularity of foveal and perifoveal reflexes; irregular distribution of the capillary ends; complete or almost complete absence of macular yellow. The first two features in this description are consistent with our own observations on the appearance of the maculofoveal area. The macular and foveal reflexes were absent or abnormal in all our patients, and the retinal capillaries were abnormally close to the presumed foveal area. In some cases these capillaries even crossed the horizontal meridian, with resulting absence of the avascular zone typical of the normal macula (Figs. 1,2). In two patients the fluorescein angiography pattern from the presumed macular area was similar to that emitted from more peripheral parts of the fundus, probably because of the absence of macular pigments which would normally filter the background choroidal fluorescence (Fig. 3). In the other five varying amounts of fluorescence were emitted from the presumed macular areas. On the basis of our findings we assume that the fluorescein angiographic appearance of the maculofoveal area probably varies in different patients and depends on the amount of macular pigment present. This conclusion does not entirely corroborate Waardenburg's contention that macular pigment is totally or almost totally absent.

Our patients showed a high incidence of tropias $(9 / 15)$ and abnormal head postures (12/15). Since the overall prevalence of tropias in the general population is not higher than $3 \%,{ }^{\prime \prime \prime}$ and the incidence of 


\section{Isolated Foveal Hypoplasia}
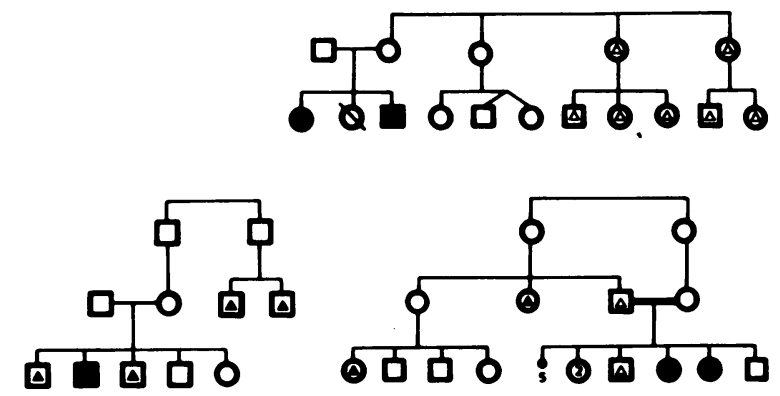
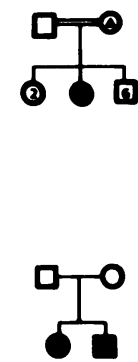

Fig. 4 Pedigrees of nine families. Three patients were unable to supply genetic data.
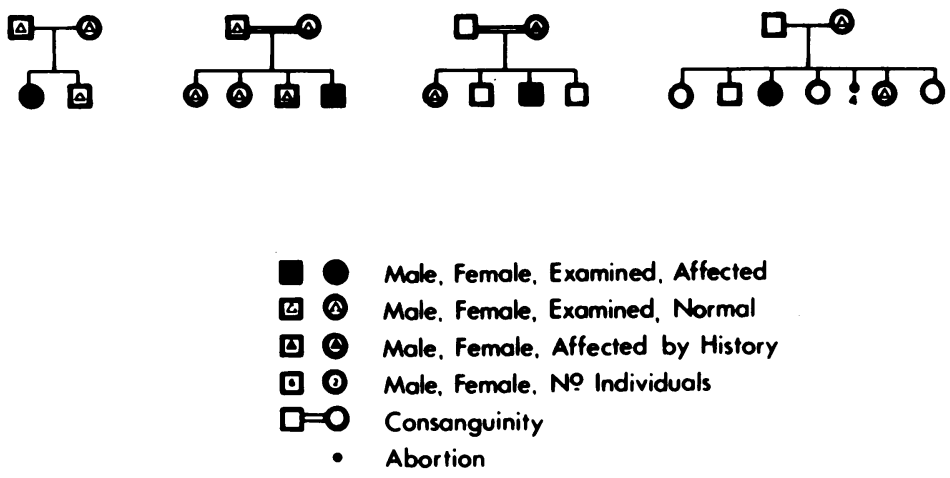

abnormal head posture is probably even lower, it is highly probable that the frequent occurrence of these findings in our patients is associated with foveal hypoplasia.

Ten of the 12 patients who underwent ERG achieved normal results. This, together with their normal colour vision, indicates that their retinal function was normal but does not exclude the possible existence of a localised foveal defect which remains undetected in the overall ERG response. The normal latency and slightly diminished amplitude revealed by the VER is suggestive of impaired foveal function but normal nervous conduction in this disorder.

Impaired visual acuity and macular anomalies are often found to be correlated with abnormal colour vision. The finding of normal colour vision in all but one of the patients treated is therefore surprising, though a similar lack of correlation between visual acuity and colour vision is also found in some other diseases, such as ocular albinism." More sophisticated tests might have revealed defects in colour vision undetectable by the pseudoisochromatic plates. However, since most of our patients were small children with low visual acuity, such tests could not be employed.
Foveal hypoplasia has been reported in association with albinism, aniridia, and occasionally achromatopsia. ${ }^{1-3}$ None of our 15 patients was albinotic in appearance. In all cases the irides were of normal appearance and did not transilluminate. The fact that nine of the patients were female also argues against a diagnosis of X-linked ocular albinism, since this disorder has rarely been reported in females. The defective colour vision and the pronounced photophobia characteristic of achromatopsia were absent. Other than foveal hypoplasia, with its accompanying nystagmus and low visual acuity, no anatomical ocular defects or systemic abnormalities were found. Nystagmus and low visual acuity in infancy may result from a number of factors, but when they are the sole findings which accompany the characteristic appearance of the fovea they should be helpful clinically in distinguishing isolated foveal hypoplasia from the other disorders mentioned above.

The literature contains only a few reports of foveal hypoplasia as an isolated anatomical finding. ${ }^{-2-9}$ One such study was carried out by Curran and Robb;" their findings were not significantly different from our own.

In a few cases of macular hypoplasia described by Duke-Elder ${ }^{2}$ histological examination showed that 
the retina at the posterior pole had remained at the stage of differentiation normally exhibited in the sixth month in utero. Hendrickson and Yuodelis ${ }^{12}$ showed that a small foveal depression first develops in the fetus at 24-26 weeks, as the ganglion and inner nuclear layer cells move laterally. At birth the centre of the fovea contains only a single layer of short, thick cones with immature short outer segments. These authors concluded that the fovea normally achieves maturation between 15 and 45 months of age. It is possible that in our patients the structure of the retina in the central area resembles that at the periphery, showing persistence of ganglion cells and nuclear layers.

Henkind ${ }^{13}$ studied the development of the foveal avascular zone in experimental animals. $\mathrm{He}$ suggested that it occurs as a result of capillary closure after birth, is independent of vision, and that the vessels occasionally seen traversing this zone represent a persistence of the fetal vasculature. The above description might apply also to foveal hypoplasia, but confirmatory embryological and histological evidence is lacking.

No definite hereditary pattern could be established in our study. Autosomal recessive inheritance has been postulated." Although our findings do not contradict his possibility, they cannot be taken as confirmation. Isolated foveal hypoplasia is characterised by variable expressivity, and the gene appears to have a low degree of penetrance. Multifactorial inheritance should be considered as another possibility, because of the absence of a clear pattern of inheritance or obvious familial aggregation. The data obtained from the families of our patients seem rather to suggest that isolated foveal hypoplasia might be another example of genetic heterogeneity with different genetic and possibly also non-genetic aetiologies.

Although our patients showed poor visual acuity, functional capacity was quite satisfactory in each case. The presence of nystagmus and poor vision in children and infants without any other ocular findings should prompt the ophthalmologist to carry out a thorough fundal examination of the maculofoveal area. The fundal findings in isolated foveal hypoplasia, though quite typical, are very subtle and often difficult to detect, especially because of the accompanying nystagmus. For this reason we suspect that foveal hypoplasia is more common than is generally believed.

\section{References}

1 François J. Heredity in ophthalmology. St Louis: Mosby, 1961: 153,519 .

2 Duke-Elder S. System of ophthalmology. St Louis: Mosby, 1963: $3(2): 652-3$.

3 Waardenburg PJ. Genetics and ophthalmology. Assen: Royal Van Gorcum, 1963; 2: 1722-3.

4 Yoshizumi MO. Thomas JV, Hirose T. Foveal hypoplasia and bilateral 360-degree peripheral retinal rosettes. Am J Ophthalmol 1979:87: 186-92

5 O'Donnell FE Jr. Pappas HR. Autosomal dominant foveal hypoplasia and presenile cataracts: a new syndrome. Arch Ophthalmol 1982: 100: 279-81.

6 Holm E. Hereditary nystagmus. Acta Ophthalmol (Kbh) 1926;4: 20-7.

7 Koyanagi Y. Ueber den genetischen Zusammenhang zwischen dem hereditaren Nystagmus und Bulbusalbinismus. Klin Monatsbl Augenheilkd 1927; 79: 43-8.

8 Uemura $Y$, Kumanomido A. The study on macular findings in "amblyopic eye". Nippon Ganka Gakkai Zasshi 1961; 65: $2264-71$.

9 Curran RE. Robb RM. Isolated foveal hypoplasia. Arch Ophthalmol 1976; 94: 48-50.

10 Nawratzki I, Oliver $M$. The screening of pre-school children for the early detection of certain ocular defects. Excerpta Med Int Congr Ser No. 222. 1970: 978-82.

11 O'Donnell FE Jr. Green WR. In: Duane TD, ed. The eye in albinism. Clinical ophthalmology. Philadelphia: Harper and Row, 1984; 4: chapter 38: 6-13

12 Hendrickson AE, Yuodelis C. The morphological development of the human fovea. Ophthalmology 1984: 91: 603-12.

13 Henkind P. Bellhorn RW. Murphy ME, Roa N. Development of macular vessels in monkey and the cat. BrJ Ophthalmol 1975; 59: $703-9$.

Accepted for publication 20 November 1986. 